\title{
A Breakthrough in the Logical Deduction about the Cognition Theory
}

\author{
Dongkai Li \\ Independent Scholar
}

\begin{abstract}
The contradiction would produce the power only in the condition that this contradiction stays within a substance. The movement power for the cognition is not produced by the contradiction between people's thinking and the objective things, for the thinking and the objective things are not in a same substance, which is Hegel's problem. Then, where is the power for people's cognition from? This paper has a conclusion as this: The "Ego" and the "Nonego" are a pair of contradiction within a person's body. The cognition is a kind of people's movement. So, the cognition is the process moved by the power from the "Ego" and the "Nonego" of a person's body.
\end{abstract}

Keywords: contradiction, cognition, people, Ego, Nonego

\section{Hegel's Problem in His Ontology and Cognition Theory}

Kant explained that there was some kind knowledge existing beyond people's experience by his transcendental theory. However, his problem was making the natural object apart from the subjective cognition process. Hegel's contribution was combining the objective and the subjective by his theory of cognition movement.

Hegel realized there was the contradiction between the objective world and the subjective cognition. As per theory of Aristotle, he knew the contradiction within a substance would produce the power for movement. Then Hegel came to a supposition that it is just the movement power from the contradiction between the subjective and the objective that makes the cognition process go on continuously.

In order to establish this great suppose, Hegel produced his ontology theory as this, "the thinking is the existing substance." By his meaning, the objective thing and the subjective idea should be a pair of contradiction within the substance of "thinking;" this contradiction within "thinking" would produce the power for movement of the cognition.

But, the problem is that the "thinking" cannot be an independent substance consisted of a pair of contradiction, for people's thinking cannot be there without people. As per Aristotle's principle of the substance, an existing substance must be independent. Obviously, thinking does not have the nature of independence. Without people, there is no thinking. So, Hegel's ontology conclusion of "the thinking is the substance" is not reasonable.

Since the thinking is not such a substance, then, the subjective and the objective shall not stay in the

Dongkai Li, independent scholar, China; main research field: Ontology, Cognition, and People.

The author ever attended the 22nd and 23rd World Congress of Philosophy with his 6 papers approved for discussion by the Congress. His published philosophy book is What Is the Existence by XUELIN ISBH. His has another two new philosophy books ready for publishment, The Existence of People and Comment on Chinese Philosophy. 
thinking as a pair of contradiction. If a pair of contradiction does not stay within a same substance, then, this contradiction would never produce power for movement. So, by this sense, I should say the cognition movement is not pushed by the power from the contradiction between the subjective and the objective. So, I should say Hegel's cognition theory is not reasonable.

\section{How to Resolve Hegel's Problem}

Once again I state here clearly, Hegel's problem is in these two aspects:

(1). As per the deduction made by Aristotle, the substance should be an independent existence powered by a pair of contradiction within its body, but the thinking is not such a substance.

(2). The contradiction would produce the power only in the condition that this contradiction stays within a same substance. So, the movement power for the cognition is not produced by the contradiction between people's thinking and the objective things, for the thinking and the objective things are not in a same substance.

Shall we say people such a substance with a pair of contradiction within a person's body? What is the contradiction inside a person?

The first condition for a person's living is the satisfaction of his or her natural body demand. There are two aspects involved for the satisfaction of the natural demand: one is the healthy body with its natural demand function system; another is the object in the world to serve the demand.

The healthy natural demand function system is in the people's body, and the objective thing to serve the demand is outside of the body. Here is a question: How does the person take the outside object to serve his body's demand? Let us check the process of people's action of looking for the object for serving his body demand.

When "I" had the demand for water, my body function would make me feel thirsty. But, the water is not in my body. In my body, I have no water to serve this demand. I must take action looking for the water in the nature.

What I need is the water, not stone, not the bread. So, I must confirm the objective water is the water wanted.

This judgment is made by comparing the objective object with the knowledge or idea in people's consciousness.

If there is the idea or image about the water in my consciousness, when I see the water, I would check this objective water with this idea. If the object complying to this idea, then, I would confirm that object is the one I want.

If I do not have the idea about the water, then, I cannot confirm an object as water or not. For example, if you do not know a person, then, you would not find him even if he is just standing at your side.

So, we would say without the knowledge or ideas in a person's consciousness, the person would not find the object to serve his body demand. The consciousness is in a person's body, but, these idea or knowledge in the consciousness cannot serve the demand of the body. Here is a contradiction in a person, the demand of the body and the idea in the consciousness. This is the contradiction producing the power of movement of a person as a substance.

Here, I call the natural body with its demand function system as "ego," the idea refers to the outside objective thing in the consciousness as "Nonego." The "Ego" and the "Nonego" are a pair of contradiction within a body. 
The cognition is a kind of people's movement. So, I could say the cognition is the process moved by the power from the "Ego" and the "Nonego" of a person's body. The cognition process formula should be as following:

"EGO"+"Nonego" $\rightarrow \rightarrow$ Power to MOVE (N times) $\rightarrow \rightarrow$ Feeling (N times) $\rightarrow \rightarrow$ Idea (N numbers)+Thinking $(\mathrm{N}$ times $) \rightarrow \rightarrow$

Knowledge (N numbers) $\approx$ Object $\rightarrow \rightarrow=$ Object

All people's knowledge or the truth comes from this movement of cognition.

\section{Works Cited}

Dongkai, Li. What Is the Existence.

Georg, Wilhelm Friedrich Hegel. Logic.

Iimmanuel, Kant. Kantian Epistemology. 